\title{
O SISTEMA JURISDICIONAL DA UNIÃO EUROPEIA E O INSTITUTO DO REENVIO PREJUDICIAL COMO INSTRUMENTO DE COESÃO DO BLOCO
}

\section{THE JURISDICTIONAL SYSTEM OF THE EUROPEAN UNION AND THE INSTITUTE OF HARMFUL REVIEW AS A CO-INSTRUMENT OF THE BLOCK}

\section{MAXILENE SOARES CORRÊA}

RESUMO: O escrito se ocupa do sistema jurisdicional da União Europeia, ressaltando a importância do instituto do reenvio prejudicial. Primeiramente, aborda elementos da história da integração europeia e a evolução do sistema jurisdicional, observando o surgimento dos Tribunais Europeus e as suas modificações ao longo dos anos. Depois, trata especificamente sobre o Tribunal de Justiça da União Europeia, composto do Tribunal de Justiça propriamente dito, do Tribunal Geral e dos tribunais especializados, no que toca o funcionamento, a composição e a competência de cada um deles. Analisa, por fim, o reenvio prejudicial, enquanto uma ponte entre as jurisdições nacionais e a jurisdição europeia, e um instrumento fundamental à preservação da uniformidade na aplicação e interpretação do direito da União Europeia e consequentemente, fundamental à coesão do bloco.

PALAVRAS-CHAVE: Sistema Jurisdicional da União Europeia - Tribunal de Justiça da União Europeia - Reenvio Prejudicial

ABSTRACT:This writing is about the judicial system of the European Union, highlighting the importance of the preliminary ruling. First, it discusses elements of the history of European integration and the development of the judicial system, observing the emergence of the European Courts and its changes over the years. Then comes specifically on the Court of Justice of the European Union, composed of the Court itself, the General Court and specialized courts regarding the functioning, composition and competence of each of them. Analyzes, finally, the preliminary ruling, as a bridge between national courts and the European court, and a key instrument for the preservation of uniformity in the application and interpretation of European Union law, and consequently, essential for the cohesion of European countries. KEY-WORDS: Judicial System - European Union - Court of Justice of the European Union

\section{INTRODUÇÃO}

O surgimento das comunidades europeias deu origem a um direito novo, autônomo, cuja finalidade é reger, no contexto multifacetado da União, as relações dos cidadãos, das instituições e dos próprios Estados: o Direito da União Europeia. Tal é composto não só das normas existentes nos Tratados - direito originário, mas também dos atos normativos emanados das instituições da União direito derivado. Também lhe compõe um agrupamento de princípios jurídicos que foram sendo reunidos, apurados e explicitados ao longo dos anos.

Para que uma União de direito exista de fato, no entanto, não basta a presença de uma lei comum ${ }^{1}$. É imperioso que esta lei seja interpretada e aplicada de forma uniforme por todos os seus destinatários. Por esta razão, é necessário que exista

${ }^{1}$ CAMPO, J. PEREIRA, A. CAMPOS, J. O Direito Processual da União Europeia. 2 ed. Fundação Calouste Gulbenkian. Lisboa. 2014. p. 27.

${ }^{1}$ Mestranda em Direito Internacional Público e Europeu na Universidade de Coimbra, em Portugal. Possui pós-graduação em Relações Internacionais. É graduada em Direito pela Universidade Federal de Goiás, instituição da qual recebeu bolsa de monitoria nas disciplinas de Teoria Geral do Estado e Direito Internacional Público. Atua como advogada e professora do curso de Direito da FACEG em Goianésia-GO. maxilene.scorrea@gmail.com 
instâncias jurisdicionais responsáveis de assegurar sua plena eficácia. ${ }^{2}$

O Sistema jurisdicional Europeu, desde o seu nascimento, está assente em dois pilares: as jurisdições nacionais e a jurisdição europeia propriamente dita. ${ }^{3}$ Aos tribunais nacionais foram atribuídas competências gerais, como tribunais comuns na ordem jurídica, para aplicar o direito da União. Por outro lado, para garantir a correta interpretação e aplicação das normas jurídicas comuns à coletividade europeia, bem como para controlar e sancionar os atos das instituições, órgãos, organismos, Estados-Membros e até mesmo dos próprios particulares, existe o Tribunal de Justiça da União Europeia, que inclui o Tribunal Geral e os Tribunais Especializados.

Partindo disso, este escrito tratará da organização judiciária da União Europeia. Em um primeiro momento, serão realizados alguns apontamentos sobre a integração europeia e a evolução do sistema jurisdicional, ressaltando o surgimento dos Tribunais Europeus e as suas modificações ao longo dos anos, e, principalmente entendendo o papel do sistema jurisdicional no processo de integração.

Posteriormente, trataremos especificamente sobre o Tribunal de Justiça, composto do Tribunal de Justiça propriamente dito, do Tribunal Geral e dos tribunais especializados, detalhando o

${ }^{2}$ MARTINS, Ana Maria Guerra. Algumas reflexões sobre a reforma do Sistema Jurisdicional comunitário. In. Em torno da Revisão do Tratado da União Europeia. Livraria Almedina. Coimbra, 1997. p. 205.

${ }^{3}$ RAMOS, Rui Manuel. O Tratado de Nice e a Reforma do sistema jurisdicional comunitário. In. Rev. Direito e justiça, Vol. XVIII, tomo II, 2004. p. 194. funcionamento, a composição e a competência de cada um deles. O objetivo é demonstrar a importância de cada Tribunal no quadro institucional e sua função na manutenção da ordem jurídica na União Europeia.

Por fim, para ressaltar a função do Tribunal de Justiça de garantidor da uniformidade na aplicação e interpretação do Direito da União Europeia, analisaremos o processo de reenvio prejudicial, um mecanismo clássico de cooperação judicial, de especial importância para o sistema jurisdicional europeu, considerando seu papel de aproximação dos juízes nacionais e a jurisdição europeia, promovendo assim uma maior eficácia do Direito da União.

\section{A evolução do sistema jurisdicional europeu à luz da história da integração europeia.}

É necessário iniciarmos retomando alguns pontos da história da integração europeia, ainda que de forma breve, de modo a percebermos os contornos que o sistema jurisdicional europeu foi tomando ao logo desse processo. O sistema jurisdicional, bem como as outras instituições, foram fundados com determinadas conformações, porém, com o passar das décadas, estas foram se modificando, de forma a adaptarem-se às novas perspectivas e objetivos dos países europeus, até se apresentar tal como se apresenta hoje. 
No ano de 1951, no qual um conjunto de países europeus ${ }^{4}$ iniciou uma união econômica e política através da Comunidade Europeia do Carvão e do Aço (CECA). Esta instituição possuía uma estrutura quadripartida formada por: Alta autoridade, Conselho, Assembleia Parlamentar e Tribunal. Este é o gérmen da estrutura existente hoje. Ainda na mesma década, em 1957, os Tratados de Roma instituíram a Comunidade Económica Europeia (CEE) ou Mercado Comum e a Comunidade Europeia da Energia Atômica. Isto abriu espaço para uma década de 60 caracterizada por um considerável avanço econômico e pelo alargamento do comércio intracomunitário. Estas duas outras comunidades tinham a mesma estrutura da CECA, ou seja, contavam também, inicialmente, com quatro órgãos cada.

Assim, resultou que no quadro da CECA havia um órgão jurisdicional, da mesma forma que eram previstos tribunais nos quadros da Comunidade Económica Europeia e da Comunidade Europeia da Energia Atômica. Porém, não se justificava a multiplicidade de instituições chamadas a cumprir missões análogas, motivo pelo qual a Convenção de $1957^{5}$, assinada no mesmo dia dos Tratados de Roma, previu um único tribunal. As questões jurídicas suscitadas pela interpretação dos Tratados das três comunidades passaram a encontrar solução em um único Tribunal, chamado de Tribunal de Justiça das Comunidades Europeias,

\footnotetext{
${ }^{4}$ Bégica, Holanda, Luxemburgo, Alemanha Ocidental, França e Itália.

5 "Relativa a certas instituições comuns"
}

mais tarde designado de Tribunal de Justiça da União Europeia.

Em 1973 houve o primeiro alargamento com a adesão da Dinamarca, da Irlanda, e do Reino Unido. Nos anos 80 aderiram Grécia, Espanha e Portugal. Com o passar das décadas e os sucessivos alargamentos da União, considerando as novas competências do Tribunal de Justiça e a crescente busca dos Tribunais nacionais e dos sujeitos de direito em geral ao Tribunal de Justiça, houve um aumento considerável das causas nessa alta jurisdição. Isso causou um congestionamento do Tribunal e uma conseqüente demora na prestação jurisdicional.

O aumento do número de juízes logo se mostrou uma solução limitada. A criação de um outro tribunal poderia melhorar a proteção das partes envolvidas em processos que exijam um exame mais aprofundado de fatos complexos. A existência desse segundo tribunal, serviria a dois objetivos principais. Inicialmente, instituiria o duplo grau de jurisdição a nível europeu. Em segundo lugar, desafogaria o Tribunal de Justiça permitindo que este concentrasse seus esforços em sua função primordial, qual seja, a de assegurar a aplicação uniforme do Direito Comunitário.

Em 1986 aconteceu a assinatura do chamado Ato Único Europeu, com o objectivo de fortalecer a coesão económica e social entre os países. O Ato Único impulsionou iniciativas comuns em matéria de política externa e segurança. Os Estados-Membros, aproveitando o ensejo do Ato Único Europeu em 1987, aditaram aos 
Tratados disposições que autorizavam a criação de uma nova jurisdição comunitária. O Conselho das Comunidades Europeias, a pedido do Tribunal de Justiça e após pareceres da Comissão e do Parlamento, instituiu o Tribunal de Primeira Instância das Comunidades Europeias.

Foi em 1992, através do Tratado de Maastricht, que fundou-se a União Europeia. Este tratado alterou os anteriores, trazendo novos princípios e regras inclusive em relação aos Direitos Humanos e fundamentais. Houve avanços no que toca à justiça em assuntos internos e também política externa. Foi introduzida a ideia de cidadania europeia. O Euro tornou-se moeda comum. Porém, nas palavras do Professor Cruz Vilaça a inovação de maior alcance do ponto de vista da evolução do sistema jurisdicional reside no reconhecimento ao Tribunal de Primeira Instância competência para se ocupar de todas e quaisquer espécies de acções e recursos diretos, sejam quais forem os autores ou recorrentes (particulares, Estados-Membros e instituições da comunidade) e os domínios do direito comunitário a que dizem respeito. ${ }^{6} \mathrm{Ou}$ seja, Maastricht alargou as competências do Tribunal de Primeira Instância.

Este Tribunal sofreu uma relevante reforma com o Tratado de Nice, especialmente no que se refere às competências. O Tratado alargou ainda os poderes do Tribunal, conferindo-lhe competência genérica, de natureza residual e aumentou sua

\footnotetext{
${ }^{6}$ VILAÇA, José Luís da Cruz. A evolução do sistema jurisdicional comunitário: antes e depois de Maastricht in Direito Comunitário e construção europeia, BFD, Stvdia Jvridica, 38, Coimbra Editora, Coimbra, 1999. p. 29.
}

função interpretativa e aplicadora dos tratados ${ }^{7}$. Foi-lhe atribuída verdadeira autonomia. O Tratado de Nice trouxe ainda a possibilidade de criação das chamadas câmaras jurisdicionais, criadas para atuar em causas de matérias específicas, como mais uma alternativa para o abarrotamento do Tribunal de Justiça e como um meio de atender ao princípio da especialidade da jurisdição.

No início dos anos 2000, houve um grande número de adesões, chegando a 25 paísesmembros (hoje são 28). A elevada quantidade de partes tornou cada vez mais complexo o processo de tomada de decisões, bem como evidenciou outras falhas na estrutura institucional da União.

Por este motivo, em 2007, foi firmado o Tratado de Lisboa, com o objetivo de melhorar o funcionamento da União através de reformas institucionais. Foi reduzida toda a estrutura a dois tratados principais: O Tratado da União Europeia e o Tratado sobre o funcionamento da União Europeia. Além disso, o Tratado de Lisboa modificou o processo de tomada de decisões, deu mais peso ao Parlamento Europeu, eliminou uma séria de instituições obsoletas, criou a figura do presidente do Conselho Europeu e fez com que a Carta dos Direitos Fundamentais da União Europeia fosse juridicamente vinculante a todos os Estados-membros.

No âmbito do Sistema Jurisdicional, o Tratado de Lisboa trouxe a arquitetura que se apresenta hoje. Uma estrutura complexa composta

\footnotetext{
${ }^{7}$ RAMOS, Rui Manuel. O Tratado de Nice e a Reforma do sistema jurisdicional comunitário. In. Rev. Direito e justiça, Vol. XVIII, tomo II, 2004. p. 207.
} 
pelo Tribunal de Justiça da União Europeia, o Tribunal Geral (antigo Tribunal de Primeira Instância), e os tribunais especializados (uma evolução da noção de câmaras especializadas).

A partir do Tratado de Lisboa, o artigo 19², $\mathrm{n}^{\circ} 1$ do Tratado da União estabelece que:

"O Tribunal de Justiça da União Europeia inclui o Tribunal de Justiça, Tribunal Geral e tribunais especializados. O Tribunal de Justiça da União europeia garante o respeito do direito na interpretação e aplicação dos tratados"

Estes três órgãos jurisdicionais, juntamente com as jurisdições nacionais de cada Estado Membro, formam o sistema jurisdicional da União Europeia. Nesse sentido, o que se percebe é que o sistema jurisdicional opera um papel fundamental de propulsor da integração. ${ }^{8} \mathrm{Ou}$ seja, é essencial para a construção de uma União de Direito.

Uma vez analisados, à luz da história, os contornos do sistema jurisdicional europeu, cabenos, a diante, no segundo capítulo, examinar cada um dos tribunais que compõem o Tribunal de Justiça da União Europeia, no que tange sua composição, competência e funcionamento.

\section{O Tribunal de Justiça da União} Europeia.

O Tribunal de Justiça da União Europeia se desdobra em três jurisdições que se distinguem hierarquicamente e também do ponto de vista das

\footnotetext{
${ }^{8}$ Sobre isso professora Ana Maria Guerra Martins diz que "O TJ tem sido ao longo da história da integração o principal motor da integração europeia”. MARTINS, Ana Maria Guerra. Algumas reflexões sobre a reforma do Sistema Jurisdicional comunitário. In. Em torno da Revisão do Tratado da União Europeia. Livraria Almedina. Coimbra, 1997. p. 207.
}

matérias que se ocupam. O Tribunal de Justiça propriamente dito é a jurisdição de topo, que garante o respeito ao Direito da União, quanto a sua interpretação e aplicação. O Tribunal Geral, por sua vez, é uma jurisdição de base, competente para conhecer, em primeira instância, a maior parte das ações e recursos previstos nos Tratados. Suas decisões são passíveis de recursos ao Tribunal de Justiça limitado a questões de direito, nas condições e limites previstos no Estatuto do Tribunal. Os tribunais especializados são encarregados de conhecer em primeira instância certas categorias de recursos em matérias específicas.

2.1 Tribunal de Justiça propriamente dito

O Tribunal de Justiça da União Europeia, situado em Luxemburgo é fundamental na estrutura orgânica da União. Trata-se de um "órgão inteiramente independente das demais instituições e governos dos Estados-membros, com jurisdição própria e competência exclusiva em determinadas matérias". ' João Mota de Campos, Antônio Pereira e João Luiz Mota de Campos chamam a jurisprudência do Tribunal de "progressista, no melhor sentido da expressão"10, já que ousada, e disposta a estabelecer um conjunto de princípios fundamentais no Direito da União.

O Tribunal de Justiça, como principal instituição jurisdicional da União, está em uma posição de influência. Como jurisdição

${ }^{9}$ CAMPOS, J. CAMPOS, J. PEREIRA. A. Manual de Direito Europeu: O sistema institucional, a ordem jurídica e o ordenamento econômico da União Europeia. 7. ed. Coimbra Editora. Coimbra. 2014. p. 181.

${ }^{10}$ CAMPO, J. PEREIRA, A. CAMPOS, J. O Direito Processual da União Europeia. 2 ed. Fundação Calouste Gulbenkian. Lisboa. 2014. p. 29 
constitucional, contribui para o equilíbrio institucional da União, nomeadamente nas relações entre o Conselho, a Comissão e o Parlamento Europeu. Ademais, tendo os Tratados como constitutivos afere a validade dos atos das instituições da União. É também um tribunal administrativo, já que impõe às instituições e órgãos da União Europeia o respeito ao princípio da legalidade. Além disso, é a jurisdição responsável pela interpretação e aplicação uniformes do Direito da União exercendo diálogo com os tribunais nacionais de modo a garantir a unidade, a coerência e a eficácia das normas do Direito Comunitário.

É importante ressaltar que o Tribunal de Justiça não tem relação hierárquica com as jurisdições nacionais. Assim, não funciona com um tribunal de recurso para as decisões internas ou como uma suprema corte em um sistema federal.

No que toca a sua composição, o Tribunal de Justiça é composto por um juiz por EstadoMembro, que escolhem entre si um presidente pelo período de três anos. O Tribunal é assistido por oito advogados-gerais. Esse número pode ser aumentado por decisão unânime do Conselho, caso solicitado. ${ }^{11}$ Os juízes e os advogados-gerais são nomeados pelos Governos dos Estados por um período de seis anos, renovável. São escolhidos de entre "personalidades que ofereçam todas as garantias de independência e reúnam as condições exigidas, nos respectivos países, para o exercício das mais altas funções jurisdicionais, ou que sejam

${ }^{11}$ Arts. $19^{\circ}, \mathrm{n}^{\circ} 2$ do TUE e $252^{\circ}$ do TFUE jurisconsultos de reconhecida competência". ${ }^{12}$ A cada três anos há uma substituição parcial dos juízes e dos advogados gerais.

O Tratado sobre o Funcionamento da União Europeia também prevê um comitê composto por sete personalidades de alto perfil jurídico. Este comitê tem a finalidade de dar pareceres sobre a adequação dos candidatos às funções para as quais são propostos, e assim, garantir uma criteriosa escolha dos juízes e advogados gerais. ${ }^{13}$

O Advogado Geral tem o dever de apresentar publicamente, com imparcialidade e independência, conclusões fundamentadas sobre as causas que requeiram sua intervenção. Ele não representa determinado interesse, não é acusador nem ministério público. ${ }^{14}$ Trata-se de um membro independente do Tribunal, livre de qualquer pressão das partes e da responsabilidade de julgar. As conclusões do Advogado-Geral encerram a fase oral do processo e são publicadas na Coletânea da Jurisprudência do Tribunal de Justiça em anexo aos acórdãos. Assim, constituem textos de relevância na jurisprudência.

Para garantir a máxima independência dos juízes e advogados gerais suas remunerações são fixadas pelo Conselho ${ }^{15}$, sendo assegurado além do desafogo pecuniário durante o exercício do cargo, uma pensão durante o período de três anos após a cessação de suas funções, no caso de não terem

\footnotetext{
${ }^{12}$ Art. $253^{\circ}$ do TFUE

${ }^{13}$ Art. $255^{\circ}$ do TFUE

${ }^{14} \mathrm{O}$ TJ manifestou-se nesse sentido no Despacho de 04.02.2000, Emesa Sugar C-17/98, Colet., p. I-1675, nº15.

${ }^{15}$ Art. $243^{\circ}$ TFUE
} 
adquirido direito a uma pensão de reforma. Além disso, os juízes e advogados gerais gozam de imunidade de jurisdição nos termos dos artigos $3^{\circ} \mathrm{e}$ $8^{\circ}$ do Estatuto do Tribunal (ETJ), sendo também inamovíveis durante o período pelo qual foram nomeados, por força do artigo $6^{\circ}$ também do ETJ.

Os membros do Tribunal não podem exercer funções políticas ou administrativas, nem nenhuma atividade profissional remunerada ou não, do mesmo modo que não podem atuar em causa que tenham intervindo anteriormente como agentes, consultores ou advogados ou tenham se pronunciado como membros de outro Tribunal, de uma comissão de inquérito, ou a qualquer título. ${ }^{16}$

Quanto ao funcionamento, o tribunal se reúne em "secções", em "grandes secções" ou em "Tribunal Pleno". Em geral, o Tribunal de Justiça reúne-se em secções de 3 ou 5 juízes. Cada secção tem um juiz-presidente e um juiz-relator. A "grande secção", composta por 15 juízes, acontece, sob presidência do presidente do Tribunal, sempre que um Estado-membro ou uma instituição da União que seja parte na causa solicite. Está relacionada com a dificuldade e com a importância do processo. As deliberações são consideradas válidas com a presença de 11 juízes. O Pleno é reunido apenas em casos delicados ou em causas de excepcional importância, e é presidido pelo presidente do Tribunal. ${ }^{17}$

\footnotetext{
${ }^{16}$ Art. $4^{\text {o }}$ do Estatuto do Tribunal de Justiça da União Europeia.

${ }^{17}$ Art. $16^{\circ}$ do Estatuto do Tribunal de Justiça da União Europeia.
}

Ao Tribunal de Justiça foram atribuídas competências em processos de jurisdição voluntária e em processos de jurisdição contenciosa. É também competência do Tribunal conhecer, em recurso, de decisões proferidas pelo Tribunal Geral.

Em processos de jurisdição voluntária, o Tribunal de Justiça pode ser solicitado a fornecer interpretação do Direito da União ou a reconhecer validade dos atos das instituições. Ele pode ser levado, em título consultivo, a pronunciar-se sobre a compatibilidade de certos atos com a Constituição da União.

No que tange à competência consultiva, também não contenciosa, o Tribunal de Justiça a exerce em diversos casos previstos nos Tratados. No número 11 do artigo $218^{\circ}$ do Tratado de Funcionamento da União Europeia, por exemplo, há previsão de solicitação do Tribunal para pronunciar-se sobre a compatibilidade de qualquer projeto que a União tenha em vista concluir com terceiros Estados ou com uma Organização Internacional, em relação aos Tratados. A solicitação de parecer não é obrigatória, mas uma vez solicitado, o parecer é vinculativo. Em caso de parecer negativo do Tribunal, o acordo projetado não pode entrar em vigor salvo alteração deste ou modificação dos tratados.

No exercício da competência contenciosa, o Tribunal intervém:

a) Por vezes como jurisdição internacional, quando solicitado a julgar em ação por incumprimento, a pedido da Comissão, de um Estado-Membro, do Conselho de 
Administração do Banco Europeu de Investimento ou do Conselho do Banco Central Europeu, da violação por um Estado-Membro das obrigações decorrentes do Direito da União; $;^{18}$

b) Por vezes como Tribunal Constitucional quando chamado a resolver em recurso de anulação ou recurso por omissão, conflitos de competência entre as instituições da União ou a controlar a conformidade dos atos - ou das abstenções (em relação aos Tratados ou aos princípios gerais de Direito);

c) Como jurisdição administrativa e laboral, quando deve julgar a legalidade dos atos da administração da União ou conhecer, em sede de recurso, dos litígios que opõem a União aos seus funcionários e agentes; ${ }^{19}$

d) Como Tribunal de Justiça Cível e Criminal quando julga certos comportamentos de operadores do Mercado Interno ${ }^{20}$, para aplicar as sanções pecuniárias previstas em regulamentos comunitários.

e) Como Tribunal fiscal e aduaneiro quando aplica disposições pertinentes dos Tratados ou do direito derivado em questões aduaneiras ou fiscais.

Em verdade, as competências contenciosas do Tribunal de Justiça da União Europeia são extensas e exercidas mediante um complexo sistema de vias processuais.

\footnotetext{
${ }^{18}$ Arts. $258^{\circ}-262^{\circ}$ TFUE

${ }^{19}$ Exemplo: Arts. $263^{\circ}-266^{\circ}$ TFUE

${ }^{20}$ Exemplo: Arts. $101^{\circ}$ e $102^{\circ}$ TFUE
}

Além das competências trazidas pelos Tratados (voluntárias e contenciosas), o Tribunal pode ser chamado a julgar os litígios que lhe sejam submetidos por força de uma cláusula compromissória $^{21}$. Neste caso, a competência do Tribunal de Justiça pode resultar de uma cláusula compromissória constante de uma convenção concluída pelos Estados-Membros para aplicação do Tratado, de um tratado internacional concluído pela União com terceiros Estados, de uma decisão dos representantes dos Estados-Membros reunidos no seio do Conselho, ou de um acordo interno concluído pelos representantes dos EstadosMembros.

\subsection{Tribunal Geral}

O Tribunal Geral tem sua sede na cidade de Luxemburgo e a escolha de seus membros é feita com base em critérios equivalentes àqueles utilizados na escolha dos juízes do Tribunal de Justiça. Os membros do Tribunal Geral elegem entre si um presidente pelo período de três anos, que pode ser reeleito. Os membros podem ser chamados para o desempenho de funções como juízes ou como advogados gerais. O Tribunal, normalmente, funciona em secções de três ou cinco juízes e pode se reunir em "grande secção" ou em plenária.

O Tratado de Funcionamento da União Europeia prevê que o Tribunal Geral é competente para conhecer em primeira instância dos recursos referidos nos artigos $263^{\circ}, 265^{\circ}, 268^{\circ}, 270^{\circ}$ e $272^{\circ}$ do mesmo tratado, exceto se forem interpostos

${ }^{21}$ Art. 272 TFUE 
pelos Estados-Membros, pelas instituições da UE ou pelo Banco Central Europeu, casos em que o Tribunal de Justiça é exclusivamente competente.

Esses artigos envolvem: os recursos que tenham por objeto a anulação de atos das instituições, dos órgãos ou dos organismos da UE ou as ações por omissão contra as instituições intentados pelas pessoas singulares ou coletivas; as ações e recursos interpostos pelos EstadosMembros contra a Comissão; as ações que tenham por objeto a reparação dos danos causados pelas instituições, órgãos ou organismos da UE ou pelos seus agentes; os litígios relacionadas com contratos celebrados pela União ou em seu nome que prevejam expressamente a competência do Tribunal Geral; as ações e recursos no domínio da propriedade intelectual interpostos contra $\mathrm{O}$ Instituto de Harmonização do Mercado Interno e contra o Instituto Comunitário das Variedades Vegetais; os recursos das decisões dos Tribunais especializados; os recursos interpostos das decisões da Agência Europeia dos Produtos Químicos.

Como dissemos, também é de competência do Tribunal Geral o conhecimento de algumas questões prejudiciais que lhe sejam submetidas pro força do artigo $267^{\circ}$ do Tratado de Funcionamento em matérias específicas determinadas pelo Estatuto do Tribunal. ${ }^{22}$ Porém, quando o Tribunal Geral entender que a causa demanda uma decisão susceptível de afetar a unidade ou a coerência do direito da União, pode remeter essa causa ao

${ }^{22}$ Alteração prevista pelo $\mathrm{n}^{\circ} 3$ do artigo $225^{\circ}$ do Tratado de Nice. Ou seja, realizada ainda em sede do Tribunal de Primeira Instância.
Tribunal de Justiça para que este delibere sobre ela. Quando o Tribunal Geral decide, ele próprio, a questão prejudicial, o Tribunal de Justiça pode, excepcionalmente, ser chamado a reapreciá-la.

Em regra, os acórdãos proferidos pelo Tribunal Geral em primeira instância podem ser objeto de recurso, limitado às questões de direito, para o Tribunal de Justiça.

Nos últimos anos, observou-se um aumento considerável do número de processos submetidos ao Tribunal Geral, o que tem prejudicado a rápida prestação jurisdicional ${ }^{23}$. Segundo dados do Conselho Europeu, o número de processos novos por ano aumentou de menos de 600 antes de 2010 para 912 em 2014, o que resultou na acumulação sem precedentes de 1393 processos pendentes no final de março de 2015.

Em 28 de março de 2011, o Tribunal Geral solicitou o aumento do número de juízes para 39, a fim de responder ao acréscimo do número de processos. O Parlamento então propôs que o Tribunal Geral fosse composto por um juiz por Estado-Membro e 12 juízes suplementares. Os 12 juízes suplementares seriam designados exclusivamente com base na sua adequação profissional e pessoal, independentemente da nacionalidade.

Em abril de 2015, tendo em vista a impossibilidade de um acordo sobre esta proposta, por falta de entendimento entre os governos nacionais sobre os que deveriam ter um juiz suplementar, o Conselho Europeu propôs antes

\footnotetext{
${ }^{23}$ Importa assinalar que o artigo 47. ${ }^{\circ}$ da Carta dos Direitos Fundamentais da União Europeia prevê o direito de obter uma decisão judicial num prazo razoável como garantia.
} 
uma simples duplicação do número de juízes. $\mathrm{O}$ artigo 48 do Estatuto do Tribunal passou à seguinte redação: "O Tribunal Geral é composto por: a) 40 juízes a partir de 25 de dezembro de 2015; b) 47 juízes a partir de 1 de setembro de 2016; c) Dois juízes por Estado-Membro a partir de 1 de setembro de 2019."

Os custos da reforma são bastante razoáveis. $\mathrm{O}$ aumento previsto do número de juízes e a fusão do Tribunal da Função Pública com o Tribunal Geral terão um custo estimado de 13,5 milhões de euros por ano. Além disso, os custos decorrentes desta reforma são inferiores aos 26,8 milhões de euros reivindicados em vários processos por danos decorrentes dos atrasos das decisões. ${ }^{24}$

Temos que considerar que a alternativa encontrada, em certa medida, vai contra uma tendência de especialidade que prevalecia desde o Tratado de Nice. Tendência esta que nos levaria à criação de mais tribunais especializados, ao invés de um aumento do Tribunal Geral. No entanto, a viabilidade da criação de mais tribunais especializados é discutível. Os tribunais especializados não são flexíveis, o que significa que no caso de o número de processos aumentar bastante, corre-se o risco de a jurisdição não conseguir fazer-lhes face. Além disso, aumentar-seia o risco de incoerência do direito da UE, uma vez que haveria sempre três instâncias que poderiam pronunciar-se sobre questões semelhantes, uma por via prejudicial (Tribunal de Justiça), a outra por via do recurso da decisão da instância inferior (Tribunal Geral) e a última por via de recursos

${ }^{24}$ Conselho Europeu. Comunicado de Imprensa 497/15 de 26/06/2016. diretos (tribunal especializado). Os tribunais especializados também aumentam a complexidade. Finalmente, o custo seria desnecessariamente elevado, já que cada tribunal especializado teria um Presidente e respetivo gabinete, bem como uma secretaria e outros custos fixos. ${ }^{25}$

Tribunais Especializados

O Parlamento Europeu e o Conselho podem criar Tribunais Especializados, adstritos ao Tribunal Geral, para conhecer em primeira instância certas categorias de recursos em matérias especificas. $^{26}$

A decisão do Conselho que cria um Tribunal Especializado vem com determinações sobre sua composição e a delimitação das competências a ele atribuídas. O Conselho também é responsável por nomear os membros dos Tribunais Especializados, decidindo por unanimidade. Às decisões por ele proferidas cabe recurso ao Tribunal Geral, em princípio limitado a questões de Direito, com possibilidade de recurso excepcional para o Tribunal de Justiça. Caso haja previsão no regulamento que cria o tribunal especializado, pode haver recursos também sobre as questões de facto.

No ano de 2004, o Conselho criou um tribunal especializado composto por sete juízes, com competência para julgar, em primeira instância, questões que envolvam o funcionalismo público comunitário. Este tribunal ficou designado por

25 Idem.

${ }^{26}$ Art. $257^{\circ}$ do TFUE 
Tribunal da Função Pública da União Europeia. ${ }^{27}$ Os procedimentos desse tribunal foram estruturados de forma a estimular a resolução amigável do litígio. Do ponto de vista institucional, este tribunal está no âmbito do Tribunal de Justiça, estando adstrito ao Tribunal Geral. Em assim sendo, seus membros gozam do Estatuto dos membros do Tribunal Geral. Das decisões do Tribunal da Função Pública, cabem recursos ao Tribunal Geral limitado a questões de direito, nos mesmos termos que das decisões deste último para o Tribunal de Justiça.

\section{O processo de reenvio a título} prejudicial

O reenvio prejudicial é fruto de uma adaptação de institutos existentes em alguns Estados-membros, especialmente no direito alemão e italiano, nos quais há a previsão de mecanismos prejudiciais para a corte constitucional. O sistema francês também serviu de modelo, considerando a possibilidade que prevê de envio prejudicial entre as jurisdições judiciárias e administrativas. ${ }^{28}$

Em nível europeu, está alicerçado por dois dos princípios norteadores do Direito da União Europeia: o princípio do primado sobre o direito nacional e o princípio da aplicabilidade direta.

O princípio do Primado do Direito da União significa a prevalência do Direito da União sobre todo o Direito nacional dos países membros,

${ }^{27}$ Decisão do Conselho de 2 de novembro de 2004. (2004/752/EC, Euratom)

${ }^{28}$ BROBERG, Niels. Le renvoi préjudiciel à la Cour de Justice de l'Union Européene. Édition Larcier. Bruxelles. 2013. de modo que a legislação interna que for divergente é afastada. Trata-se, portanto, de uma situação de superioridade hierárquica das normas europeias em relação às normas nacionais dos Estados-membros. Em certa medida, tal princípio, conduz necessariamente à noção de aplicabilidade direta. $\mathrm{O}$ princípio da Aplicabilidade Direta, corresponde à possibilidade de aplicação do direito europeu sem a necessidade de qualquer ato de transposição para a legislação nacional, garantindo assim a eficácia do Direito europeu dentro do bloco. ${ }^{29}$

Em suma, o direito europeu detém autonomia e primazia em relação ao direito estatal e é convertido automaticamente em direito interno, o que quer dizer que, uma vez vigentes, as normas europeias têm efeito imediato sobre os Estados e direto sobre os seus destinatários. Logo, em decorrência disso, os tribunais nacionais também se vinculam ao direito europeu.

É impossível que os Tratados tenham plena eficácia sem que as jurisdições nacionais colaborem nessa tarefa, exercendo sua competência de aplicar o direito comunitário. No entanto, "o potencial de pulverização hermenêutica da direito da União Europeia pela atividade dos tribunais nacionais é enorme, sendo imprescindível mecanismos que permitam garantir a continuidade de sentido das normas do direito da União Europeia nos vários

${ }^{29}$ MOURA, L. CAMARGOS, L. Os princípios da Aplicabilidade Direita e do primado do Direito Comunitário: Um estudo comparativo entre o Mercosul e a União Europeia a partir da noção de supranacionalidade. Revista do Centro de Direito Internacional. Vol. 12. 
Estados membros". ${ }^{30}$ Um desses mecanismos, é o reenvio prejudicial.

O Direito Comunitário é um Direito novo e complexo, regido por princípios específicos. Pode acontecer de um juiz nacional, no exercício das suas competências, ter dúvidas quanto à interpretação da norma aplicável ou quanto à validade de um ato das instituições da União. Para solucionar este impasse, existe o instituto do reenvio a título prejudicial ao Tribunal de Justiça da União Europeia, o qual apresentando-se como instituto fundamental à uniformização da aplicação e interpretação do direito comunitário.

Estabelece o artigo $267^{\circ}$ do Tratado de Funcionamento da União Europeia:

O Tribunal de Justiça da União Europeia é competente para decidir, a título prejudicial:

a) Sobre a interpretação dos Tratados;

b) Sobre a validade e a interpretação dos atos adoptados pelas instituições, órgãos ou organismos da União.

Primeiramente, é necessário esclarecer alguns termos do artigo. A expressão "a título prejudicial" deixa bastante evidente o pressuposto de existência de um litígio efetivamente pendente nos órgãos jurisdicionais nacionais. $\mathrm{O}$ instituto não existe para formulação de opiniões a título consultivo, em abstrato, sobre questões gerais e hipotéticas, mas sim para suprir a necessidade de solução de um contencioso, em concreto.

Quando o artigo traz a expressão "Tratados", refere-se ao Tratado da União

${ }^{30}$ MACHADO, Jonatas. Direito da União Europeia. 2. Ed. Coimbra Editora. Coimbra, 2014. p. 623.
Europeia, ao Tratado sobre o funcionamento da União Europeia, o Tratado de Roma, a Carta dos Direitos Fundamentais da União Europeia, bem como os protocolos anexos aos Tratados, que têm o mesmo valor jurídico destes. Enquanto os "Atos adoptados pelas instituições ou organismos da União" abarcam regulamentos, diretivas, decisões, recomendações, pareceres, e outros atos que, embora com outra designação possam produzir efeitos de Direito. Os acordos internacionais concluídos pela União também estão inseridos nesse rol. ${ }^{31}$

O artigo traz, em suas alíneas, dois objetos do reenvio: a interpretação e a validade. Tratemos de cada um deles. A alínea "a" trata de interpretação dos Tratados. No exercício da sua competência para interpretar os Tratados quando solicitado pelas jurisdições nacionais, o Tribunal de Justiça não só fixa o sentido e o alcance de uma norma. Ele, em geral, verifica se essa norma é ou não diretamente aplicável. Além disso, em inúmeros acórdãos, o Tribunal precisa as condições da aplicabilidade direta.

Quanto à apreciação da validade dos atos da União, trazida pela alínea "b", a jurisprudência do Tribunal de Justiça deixa claro que a validade não está ligada apenas à legalidade intrínseca, mas também à observância das exigências de formas, ou seja, a validade formal destes atos. O Tribunal aprecia, neste caso, se a instituição de que o ato

${ }^{31}$ CAMPOS, J. CAMPOS, J. PEREIRA. A. Manual de Direito Europeu: O sistema institucional, a ordem jurídica e o ordenamento econômico da União Europeia. 7. ed. Coimbra Editora. Coimbra. 2014. p. 181. 
emana era ou não competente, se há vícios nas formalidades essenciais do ato, se viola os Tratados ou outros Tratados Internacionais, se é contrário aos princípios gerais do Direito etc.

É importante ressaltar que um acórdão do Tribunal de Justiça da União Europeia já estabeleceu que as jurisdições nacionais não são competentes para pronunciar a invalidade dos atos das instituições comunitárias. ${ }^{32}$ Assim, caso um juiz nacional depare-se com uma questão acerca de um ato de uma instituição da União, ele pode resolver ele próprio caso sua decisão seja pela validade. Caso veja a possibilidade de invalidade do ato, deve sujeitar à apreciação do Tribunal de Justiça, obrigatoriamente.

O processo de reenvio prejudicial se apresenta como um instrumento de cooperação entre o Tribunal de Justiça e os órgãos jurisdicionais nacionais. Assim sendo, o órgão jurisdicional nacional, uma vez sendo o que tem acesso aos factos na origem do litígio, deve julgar a necessidade de uma decisão prejudicial para a solução do conflito, bem como a pertinência. É importante ressaltar que esta pode ser uma decisão de ofício do juiz, não havendo necessidade de provocação das partes. Isto porque é um instrumento fundamentalmente ligado à convicção e ao convencimento do juiz. Cabe ainda à jurisdição nacional escolher o melhor momento/ fase processual para proceder ao reenvio, considerando a economia e a utilidade processuais.

${ }^{32}$ Ac. de 22/10/87, proc. 314/85, FOTO-FROST, Colect., p. 4199.
$\mathrm{Na}$ sequência, o artigo 267 do TFUE continua com a seguinte redação:

\begin{abstract}
Sempre que uma questão desta natureza seja suscitada perante qualquer órgão jurisdicional de um dos Estados-Membros, esse órgão pode, se considerar que uma decisão sobre essa questão é necessária ao julgamento da causa, pedir ao Tribunal que sobre ela se pronuncie.

Sempre que uma questão desta natureza seja suscitada em processo pendente perante um órgão jurisdicional nacional cujas decisões não sejam susceptíveis de recurso judicial previsto no direito interno, esse órgão é obrigado a submeter a questão ao Tribunal.
\end{abstract}

$\mathrm{O}$ artigo deixa bastante claro que qualquer órgão jurisdicional pode proceder ao reenvio. No entanto, para alguns, o reenvio é obrigatório. Sobre a faculdade de reenvio, o Tribunal de Justiça orienta que os órgãos jurisdicionais nacionais tem a "faculdade ilimitada" ${ }^{33}$ de recorrer ao TJ, se considerarem que um processo neles pendente suscita questões relativas à interpretação ou apreciação de validade de disposições de direito da União com base nas quais têm que decidir. Assim, o Tribunal esclarece que nenhuma regra de direito nacional podem retirar dos órgãos nacionais a faculdade de submeterem ao TJ questões de interpretação do direito da União.

Os órgãos jurisdicionais nacionais cujas decisões não sejam suceptíveis de recurso no direito interno, por sua vez, são obrigados a encaminhar ao Tribunal de Justiça qualquer questão suscitada perante eles acerca da interpretação do Direito da União ou sobre a validade de atos das instituições da União. Nesse sentido, estão

\footnotetext{
${ }^{33}$ Acórdão de 12.06.2008, Gourmet Classic, C-458/06, Colet., p. I 4207, $\mathrm{n}^{\circ} 20$.
} 
obrigados os supremos tribunais cíveis e criminais, sociais, fiscais ou administrativos. ${ }^{34}$ Os recursos extraordinários, ou equiparáveis, não se incluem na expressão "recurso judicial previsto no direito interno", caso contrário todas as jurisdições escapariam dessa obrigação de reenvio ao Tribunal de Justiça.

No que tange às Cortes Constitucionais, há divergências sobre sua sujeição a esta obrigação. A corte constitucional alemã já decidiu que a obrigatoriedade trazida pelo artigo $267^{\circ}$ é sim aplicável a ela. Em contra-partida, a Corte Constituqionale italiana pronunciou-se no sentido de que "dada sua posição de preeminência não pode ser considerada como uma das jurisdições nacionais mencionadas no $267^{\prime 35}$ Considerando o princípio do primado do Direito da União sobre a ordem constitucional dos Estados-Membros, veementemente pregado pelo TJ, poderíamos encontrar no âmbito principiológico uma resposta pela obrigatoriedade do reenvio ao TJ pelos Tribunais Constitucionais dos Estados-Membros, o que tem se apresentado como uma tendência.

Outra dúvida suscitada é acerca da obrigação de reenvio das jurisdições inferiores nos casos em que dado o valor da causa ou a natureza do processo não há recurso ordinário das suas decisões. Até agora esta questão não foi

34 Não está previsto no Tratado um mecanismo sancionatório em caso não-reenvio, em situação de obrigatoriedade, mas é possível chegar-se à responsabilização do Estado através de uma acção por incumprimento nos termos dos artigos $258 .^{\circ}$ a $260 .^{\circ}$ do TFUE.

${ }^{35}$ Ac. de 7-3-1964 confrontada diretamente pelo Tribunal, cabendo à doutrina a discussão.

João Mota de Campos, João Luis Mota de Campos e António Pinto Pereira ${ }^{36}$ estão entre os autores que acreditam que não há obrigação de reenvio das decisões de jurisdições inferiores que não caibam recursos. Para eles, um erro de interpretação em uma decisão de um tribunal inferior, num julgamento de uma causa de pequena monta não tem proporção suficiente para comprometer seriamente a unidade de interpretação do Direito da União. Ademais, isso significaria uma sobrecarga do Tribunal de Justiça bem como um alongamento dos processos nacionais.

Outro argumento utilizado pelos que defendem a não obrigatoriedade de reenvio para os tribunais inferiores neste tipo de decisão, é baseado em uma interpretação restritiva do próprio texto do Tratado, o qual diz: "as jurisdições nacionais cujas decisões não são suceptíveis de recurso" ou seja, a obrigação de reenvio estaria relacionada com a natureza da jurisdição, e não com a natureza do processo. O critério é organicista e não propriamente processual.

Há algumas exceções da obrigação do reenvio. São elas: a) falta de pertinência da questão suscitada no processo; b) existência de

${ }^{36}$ CAMPOS, J. CAMPOS, J. PEREIRA. A. Manual de Direito Europeu: O sistema institucional, a ordem jurídica e o ordenamento econômico da União Europeia. 7. ed. Coimbra Editora. Coimbra. 2014.

CAMPO, J. PEREIRA, A. CAMPOS, J. O Direito

Processual da União Europeia. 2 ed. Fundação Calouste Gulbenkian. Lisboa. 2014. 
interpretação já anteriormente fornecida pelo Tribunal de Justiça; c) toda clareza da norma em causa.

Quanto ao procedimento, o reenvio é feito mediante um despacho do juiz nacional que suspende o processo. O Tratado não traz nem implícita nem explicitamente elementos de forma para apresentação desse despacho. O Juiz nacional goza de liberdade para redigir seu pedido de uma forma direta e simples. Porém, é indispensável que o pedido venha acompanhado de um mínimo de explicações sobre os motivos da escolha, questões de fato e de direito que julgue necessárias ao julgamento do TJ, mostrando a necessidade da questão para a solução do processo principal.

Apenas as partes no processo pendente no tribunal nacional e certas entidades que tenham interesse na decisão da questão prejudicial podem intervir no processo. $\mathrm{O}$ artigo $23^{\circ}$ do Estatuto do Tribunal elenca as estas entidades. São elas: os Estados-Membros, a Comissão, o Conselho ou o Banco Central europeu, quando esteja em causa a interpretação ou a validade de um acto deles emanado; o parlamento e o Conselho se o acto cuja validade ou interpretação é contestada tiver sido adoptado conjuntamente por estas duas instituições. Os intervenientes podem apresentar observações, mas não podem, porém alterar, alargar ou restringir o objeto, que deve permanecer tal como foi definido pelo juiz nacional do seu despacho de reenvio. O TJ tem o dever de responder aos questionamentos do juiz nacional, e apenas dele.
Após a fase escrita do processo, na qual são produzidas as observações e colhidas as informações que o Tribunal tenha solicitado, passase à fase oral. Nela os representantes das partes, dos Estados e das Instituições envolvidas no processo podem debater, em audiência pública, acerca das questões levantadas pelo juiz nacional.

O Estatuto do Tribunal prevê ainda a possibilidade de uma tramitação acelerada, por exemplo quando o processo envolve pessoas detidas. ${ }^{37}$ Há um encurtamento do prazo de alegações e observações e a dispensa das conclusões do advogado-geral. ${ }^{38}$ Existe também a chamada tramitação urgente para os processos de reenvio prejudicial relativos ao espaço de liberdade, segurança e justiça. Nesse caso, envolve ainda a redução de partes com direito de apresentar alegações ou observações e a dispensa da fase escrita do processo. ${ }^{39}$

Finalmente, a sentença do TJ é proferida, fazendo caso julgado no processo e devendo ser aplicada pelo tribunal nacional no caso concreto. É evidente que o juiz nacional pode considerar insuficiente o esclarecimento do TJ e proceder a novo reenvio, especificando novos dados de facto e novas questões jurídicas. A sentença do TJ só é vinculativa no processo em que foi solicitado a pronunciar-se. No entanto, pode

${ }^{37} \mathrm{O}$ artigo 267 do TFUE também prevê a tramitação acelerada: "Se uma questão desta natureza for suscitada em processo pendente perante um órgão jurisdicional nacional relativamente a uma pessoa que se encontre detida, o Tribunal pronunciar-se-á com a maior brevidade possível." ${ }^{38} \mathrm{Art} .23^{\circ} \mathrm{A} \S 2$ do Estatuto do Tribunal de Justiça da União Europeia.

${ }^{39} \mathrm{Art} .23^{\circ} \mathrm{A} \S 3$ do Estatuto do Tribunal de Justiça da União Europeia. 
significar a dispensa da obrigatoriedade de reenvio que impõe o art. $267^{\circ}$ aos Tribunais Supremos dos Estados-Membros, pois a questão já terá sido julgada por acórdão anterior do Tribunal de Justiça.

\section{CONCLUSÃO}

O Direito da União Europeia, enquanto ramo autônomo, é a base de legalidade para a integração da Europa. É a lei comum necessária a instauração de uma União de Direito. É impossível que o direito da União tenha plena eficácia sem que as jurisdições nacionais colaborem nessa tarefa, exercendo sua competência de aplica-lo. Daí que o sistema jurisdicional europeu esteja assente em dois pilares essenciais, as jurisdições nacionais e a jurisdição europeia. Os juízes nacionais são juízes comuns na ordem jurídica europeia. Nesse sentido, o sistema jurisdicional se apresenta como um forte elemento de integração.

Porém, a atividade dos inúmeros tribunais nacionais na aplicação do direito comum pode significar um risco à interpretação e aplicação uniformes. Por isso a promoção da uniformidade de interpretação e aplicação é uma preocupação central do direito europeu e um objetivo primordial do sistema jurisdicional. É então papel primordial do Tribunal de Justiça da União Europeia, o qual engloba $o$ tribunal geral $e$ os tribunais especializados, primar pela uniformização da aplicação e interpretação do Direito da União.

Um dos mecanismos centrais nesse aspecto uniformizador da interpretação e aplicação é o reenvio prejudicial. Através dele o Tribunal
Europeu pode manifestar-se, em concreto, acerca da interpretação dos Tratados bem como da interpretação e validade dos atos emanados de um órgão europeu. Nesse sentido, é um mecanismo fundamental de padronização da aplicação do direito europeu, necessário ao contexto heterogêneo da Europa.

O princípio do primado do direito da União sobre os direitos dos Estados-membros e o princípio da aplicabilidade direta são, em certa medida, materializados pelo instituto do reenvio prejudicial. $\mathrm{O}$ que, indubitavelmente, tem contribuído para o fortalecimento, desenvolvimento e legitimação do direito da União.

Além dessas, podemos concluir ainda por mais uma função fulcral do processo de reenvio prejudicial: tal constitui-se como uma ferramenta essencial de diálogo e cooperação entre as instâncias jurisdicionais nacionais e da União. É, metaforicamente, uma ponte que aproxima os juízes nacionais e europeus. Em assim sendo, tratase de instrumento fundamental para a coesão do sistema jurisdicional. É um elemento que contribui para que a relação entre os sistemas jurídicos nacionais e as cortes europeias seja caracterizada por complementariedade e não por confronto.

\section{REFERÊNCIAS BIBLIOGRÁFICAS}

BROBERG, Niels. Le renvoi préjudiciel à la Cour de Justice de 1'Union Européene. Édition Larcier. Bruxelles, 2013. 
CAMPO, J. PEREIRA, A. CAMPOS, J. O

Direito Processual da União Europeia. 2 ed.

Fundação Calouste Gulbenkian. Lisboa. 2014.

CAMPOS, J. CAMPOS, J. PEREIRA. A.

Manual de Direito Europeu: O sistema

institucional, a ordem jurídica e o ordenamento

econômico da União Europeia. 7. ed. Coimbra

Editora. Coimbra. 2014. p. 181.

MACHADO, Jonatas. Direito da União

Europeia. 2. Ed. Coimbra Editora. Coimbra, 2014.

MARTINS, Ana Maria Guerra. Algumas

reflexões sobre a reforma do Sistema

Jurisdicional comunitário. In. Em torno da

Revisão do Tratado da União Europeia. Livraria

Almedina. Coimbra, 1997.

MARTINS, Ana Maria Guerra. Algumas

reflexões sobre a reforma do Sistema

Jurisdicional comunitário. In. Em torno da

Revisão do Tratado da União Europeia. Livraria

Almedina. Coimbra, 1997.

MOURA, L. CAMARGOS, L. Os princípios da Aplicabilidade Direita e do primado do Direito Comunitário: Um estudo comparativo entre o Mercosul e a União Europeia a partir da noção de supranacionalidade. Revista do Centro de Direito Internacional. Vol. 12.

RAMOS, Rui Manuel. O Tratado de Nice e a Reforma do sistema jurisdicional comunitário. In. Rev. Direito e justiça, Vol. XVIII, tomo II, 2004.

VILAÇA, José Luís da Cruz. A evolução do sistema jurisdicional comunitário: antes e depois de Maastricht in Direito Comunitário e construção europeia, BFD, Stvdia Jvridica, 38, Coimbra Editora, Coimbra, 1999.

Decisões Jurisprudenciais e outros Documentos:

TJUE. Ac. de 22/10/87, , FOTO-FROST, 314/85 Colect., p. 4199.

TJUE Ac. de 12.06.2008, GOURMET

CLASSIC, C-458/06, Colet., p. I 4207, nº 20.

TJUE. Despacho de 04.02.2000, EMESA

SUGAR C-17/98, Colet., p. I-1675, nº15.

CONSELHO EUROPEU. Comunicado de Imprensa 497/15 de 26/06/2016.

CONSELHO EUROPEU. Decisão de 2 de novembro de 2004. (2004/752/EC, Euratom) 